\title{
Ten Million per Liter
}

National Cancer Institute

\section{Source}

National Cancer Institute. Ten Million per Liter. NCI Thesaurus. Code C98786.

A unit of measurement equal to ten million entities per unit of volume equal to one liter. 